\title{
Left Ventricular Hypertrophy with Strain
}

National Cancer Institute

\section{Source}

National Cancer Institute. Left Ventricular Hypertrophy with Strain. NCI Thesaurus. Code C162788.

A finding of left ventricular hypertrophy based on the analysis of diagnostic metrics that may indicate a higher risk for cardiovascular events. 